\title{
Kinetics of atrazine degradation by photocatalytic process in aqueous solution
}

\author{
O. Zahraa, ${ }^{\dagger}$ L. Sauvanaud, G. Hamard, and M. Bouchy \\ Département de Chimie Physique des Réactions - UMR 7630 CNRS-INPL \\ ENSIC, 1 rue Grandville, BP 451, F-54001 - Nancy Cedex, France
}

\begin{abstract}
The photocatalytic degradation of the herbicide atrazine has been studied using suspended titanium dioxide as catalyst. The Langmuir-Hinshelwood model is satisfactorily obeyed at initial time and in the course of the reaction. The rate of degradation is found to be enhanced by the addition of persulphate ions. Competitive degradation between atrazine and other pollutants is satisfactorily interpreted as monitored by a competitive adsorption of the reactants. As a consequence, efficient reactants such as salicylic acid and phenol delay atrazine degradation until these compounds are degraded.
\end{abstract}

\section{INTRODUCTION}

The pollution of ground water and rivers by organic pollutants is a constant concern and requires a constant improvement of water treatment so as to reach an acceptable level. Many of these pollutants are herbicides, pesticides and fungicides used in the agricultural activity, which can be carried away by the rain and pollute water resources. One of the prominent pollutants is atrazine, a photosynthesis-inhibiting persistent herbicide $\mathrm{C}_{8} \mathrm{H}_{14} \mathrm{ClN}_{5}$ used especially to kill annual weeds and quack grass.

Conventional treatments include adsorption and oxidation. Adsorption [1] on activated carbon is efficient but requires a treatment of the adsorbent in order to eliminate the adsorbed pollutant. Oxidative treatment by chlorine [2] is not totally efficient and leads to the formation of toxic products such as desethylatrazine. Advanced oxidation processes (AOPs), using hydrogen peroxide or ozone are more efficient but may be costly [3-7]. An alternative cheaper AOP is photocatalysis.

The photocatalyst is mainly a semiconductor, oxide or sulphide, and titanium dioxide $\mathrm{TiO}_{2}$ is the most interesting in view of efficiency and stability. Absorption of a photon in near UV range promotes an electron $\mathrm{e}_{\mathrm{cb}}^{-}$in the conduction band, which produces a hole $\mathrm{h}_{\mathrm{vb}}^{+}$in the valence band. If separated, these two species can migrate to the catalyst surface and act as reducer (oxygen reduction in superoxide ion) and oxidant (water oxidation in hydroxyle radical for example, or direct oxidation of the reactant) thus regenerating the catalyst electronic population. Highly reactive species such as hydroxyle radical can react on adsorbed organic molecules and abstract a hydrogen atom and therefore induce an oxidation. The main processes involved in the reaction mechanism are the following [8]:

†E-mail: Orfan.Zahraa@ensic.inpl-nancy.fr
Absorption:

$$
\mathrm{TiO}_{2}+h v \longrightarrow \mathrm{TiO}_{2}\left(\mathrm{e}_{\mathrm{cb}}^{-}+\mathrm{h}_{\mathrm{vb}}^{+}\right)
$$

Oxido-reduction:

$$
\begin{aligned}
\mathrm{h}_{\mathrm{vb}}^{+}+\mathrm{H}_{2} \mathrm{O}_{\mathrm{ads}} & \rightarrow \mathrm{OH}^{\bullet}+\mathrm{H}^{+}, \\
\mathrm{h}_{\mathrm{vb}}^{+}+\mathrm{OH}_{\mathrm{ads}}^{-} & \rightarrow \mathrm{OH}^{\bullet}, \\
\mathrm{e}_{\mathrm{cb}}^{-}+\mathrm{O}_{2} & \longrightarrow \mathrm{O}_{2}^{-\bullet}
\end{aligned}
$$

Transfers:

$$
\begin{aligned}
\mathrm{O}_{2}^{-\bullet}+\mathrm{H}^{+} & \longrightarrow \mathrm{HO}_{2}{ }^{\bullet}, \\
\mathrm{HO}_{2}{ }^{\bullet}+\mathrm{HO}_{2} & \longrightarrow \mathrm{H}_{2} \mathrm{O}_{2}+\mathrm{O}_{2}, \\
\mathrm{O}_{2}{ }^{-}+\mathrm{HO}_{2} & \longrightarrow \mathrm{HO}_{2}^{-}+\mathrm{O}_{2}, \\
\mathrm{HO}_{2}^{-}+\mathrm{H}^{+} & \longrightarrow \mathrm{H}_{2} \mathrm{O}_{2} .
\end{aligned}
$$

Degradation:

$$
\begin{aligned}
\mathrm{OH}^{\bullet}+\mathrm{RH} & \longrightarrow \mathrm{R}^{\bullet}+\mathrm{H}_{2} \mathrm{O} \\
\mathrm{R}^{\bullet}+\mathrm{O}_{2} & \longrightarrow \ldots \text { oxidation products. }
\end{aligned}
$$

Hydrogen peroxide formed can also participate in the reaction:

$$
\begin{gathered}
\mathrm{e}_{\mathrm{cb}}^{-}+\mathrm{H}_{2} \mathrm{O}_{2} \longrightarrow \mathrm{OH}^{\bullet}+\mathrm{OH}^{-}, \\
\mathrm{H}_{2} \mathrm{O}_{2}+\mathrm{O}_{2}^{-} \cdot \longrightarrow \mathrm{OH}^{\bullet}+\mathrm{OH}^{-}+\mathrm{O}_{2} .
\end{gathered}
$$

Alternative direct oxidation:

$$
\mathrm{h}_{\mathrm{vb}}^{+}+\mathrm{RX}_{\mathrm{ads}} \longrightarrow \mathrm{RX}_{\mathrm{ads}}^{+} \text {. }
$$

After several steps, a complete mineralization is often observed according to the eq. (9):

$$
\begin{aligned}
& \mathrm{C}_{\mathrm{x}} \mathrm{H}_{\mathrm{y}} \mathrm{Cl}_{\mathrm{z}}+\left(\mathrm{x}+\frac{\mathrm{y}-\mathrm{z}}{4}\right) \mathrm{O}_{2} \\
& \stackrel{\left(h v, \mathrm{TiO}_{2}\right)}{\longrightarrow} \mathrm{xCO}_{2}+\mathrm{zH}^{+}+\mathrm{zCl}^{-}+\left(\frac{\mathrm{y}-\mathrm{z}}{2}\right) \mathrm{H}_{2} \mathrm{O} .
\end{aligned}
$$


In the case of atrazine, various intermediates have been identified [10], leading to the formation of isocyanuric acid $\mathrm{C}_{3} \mathrm{~N}_{3} \mathrm{O}_{3} \mathrm{H}_{3}$ [16]. This compound is very resistant, due to the absence of $\mathrm{C}-\mathrm{H}$ bond where hydrogen can be easily abstracted by the $\mathrm{OH}^{\bullet}$ radical. The main stoichiometry is therefore:<smiles>CCNc1nc(Cl)nc(NC(C)C)n1</smiles>

The aim of this work is to study the atrazine abatement in a photocatalytic reactor and to assess the effect of various physicochemical parameters on the rate, a necessary step in designing an efficient process.

\section{EXPERIMENTAL}

Atrazine was a commercial product from ATRAPHYTEL SIPCAMPHYTEUROPE and was dissolved in de-ionised water. Titanium dioxide was DEGUSSA P25 suspended in the solution to be treated at a typical concentration of $1 \mathrm{~g} \cdot \mathrm{L}^{-1}$.

The photocatalytic reactor (cf. Figure 1) consisted in a vertical annular reactor (external diameter $8 \mathrm{~cm}$, internal diameter $6 \mathrm{~cm}$, height $110 \mathrm{~cm}$, effective volume $2 \mathrm{~L}$ ) surrounding a PHILIPS TFWN36 UV fluorescent lamp of length $120 \mathrm{~cm}$, electric power $36 \mathrm{~W}$, with an emitting wavelength range around $365 \mathrm{~nm}$ and a spectral width of $20 \mathrm{~nm}$. The lamp was cooled by air flowing freely within the open central section of the reactor. The suspension was allowed to flow upwards in the annular space. The flow was introduced in the annular space through four inlets surrounding the bottom and collected at four outlets surrounding the top so as to ensure a uniform flow. In addition, the bottom of the annular space was filled with glass beads to ensure a good homogenization before entering the irradiation section.

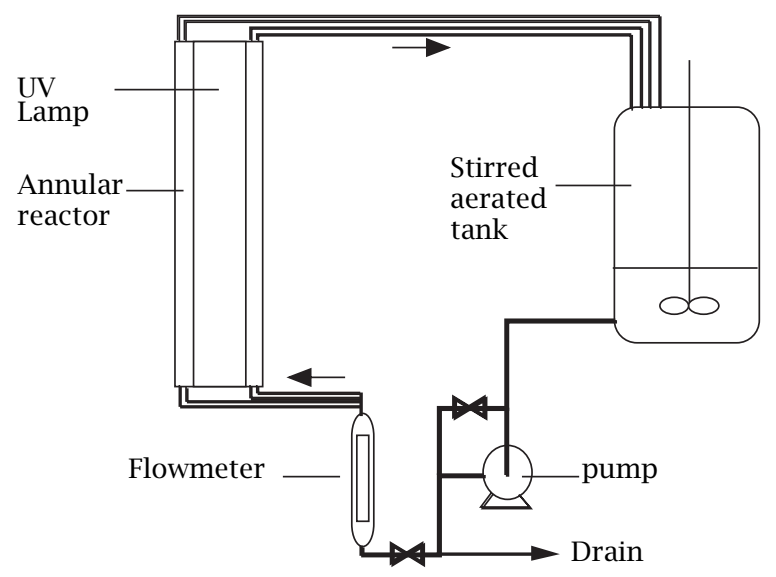

Figure 1. Experimental set-up.
The whole set-up consisted in the reactor, an aerated stirred stainless steel tank, a centrifugal pump UISGEV and a flowmeter VÖGTIN model V1376-11, with a total volume of $15 \mathrm{~L}$. The suspension was circulated in a close loop. The tubing between the tank, pump and rotameter was of stainless steel and that of the inlets and outlets of the reactor was of silicone. The flowrate was $0.35 \mathrm{~L} \cdot \mathrm{s}^{-1}$.

The disappearance of atrazine was followed by HPLC or UV spectrophotometry. Spectrophotometric measurements were carried out on a PERKIN ELMER LAMBDA-2 spectrophotometer. The wavelength of maximal absorption is $220 \mathrm{~nm}$ (extinction coefficient of $\left.35000 \mathrm{~L} \cdot \mathrm{mol}^{-1} \cdot \mathrm{cm}^{-1}\right)$. However, a maximum of absorption developed around $208 \mathrm{~nm}$ in the course of irradiation, due to the absorption of reaction products, so that absorption at $220 \mathrm{~nm}$ could be dependent on these products. It was observed indeed that the solution absorbance at $220 \mathrm{~nm}$ decreased from an initial value $\mathrm{A}_{0}$ at initial time to a limiting value $\mathrm{A}_{\infty}$ (about $60 \%$ of $A_{0}$ ). As a first approximation, for an intermediate $a b$ sorbance A, the conversion X could be estimated as:

$$
\mathrm{X}=\frac{\mathrm{A}_{0}-\mathrm{A}}{\mathrm{A}_{0}-\mathrm{A}_{\infty}} .
$$

This relationship assumes that the distribution of absorbing intermediates is constant, which is debatable, so that HPLC measurements were made in preference to spectrophotometric ones. HPLC measurements were carried out using a SPECTRA PHYSICS SP8810LC pump, a LICHROSORB C18TM column of length $250 \mathrm{~mm}$ and a SHIMADZU SPD-6A UV detector set at $220 \mathrm{~nm}$. Using a mobile phase of $60 \%$ methanol and $40 \%$ water and a flowrate of $1 \mathrm{~mL} \cdot \mathrm{min}^{-1}$, the retention time was about $10 \mathrm{~min}$. Due to the presence of $\mathrm{TiO}_{2}$ particle in the samples, it was necessary to filter these samples before the injection using a $0.2 \mu \mathrm{m}$ pore diameter nylon membrane. It was verified by spectrophotometry measurements that adsorption on the filter was negligible in the range of the concentration used.

Salicylic acid and phenol concentrations could be measured simultaneously in the same conditions.

Photocatalytic degradations were monitored following the running of the reactor in the absence of the irradiation during 1 hour so as to obtain a good mixing and to reach the adsorption equilibrium.

Considering a mean transit time in the irradiation zone of about $6 \mathrm{~s}$, it could be verified that the extent of reaction was very low over such a duration (less than 0.002 ) so that the reactor could be considered as a pseudo perfectly stirred batch reactor.

\section{PHOTOCATALYTIC DEGRADATION}

3.1. Verification of the photocatalytic nature of the reaction. The reaction has been followed by the disappearance of atrazine. As the intermediates do not 

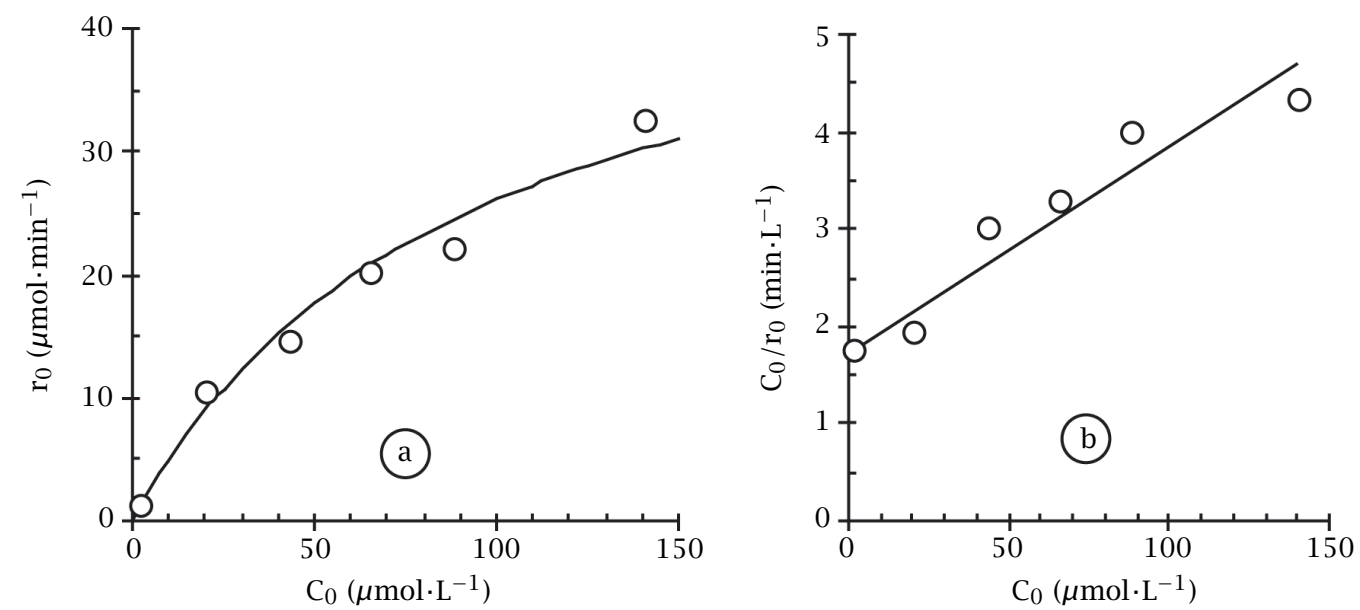

Figure 2. Variation of the initial rate of photocatalytic degradation of atrazine $\left(\mathrm{r}_{0}\right)$ with the initial concentration in reactant $\left(\mathrm{C}_{0}\right)$.

accumulate [10], this disappearance can be considered to represent the general kinetics. Moreover, it is shown below that there is no noticeable effect of the intermediates or the final product on this kinetics.

A preliminary experiment was carried out to show the photocatalytic nature of the reaction of degradation. A total degradation was observed after about 120 min of irradiation of the suspension whereas experiments carried out either with the catalyst in the absence of irradiation or without the catalyst under irradiation, showed no detectable change in atrazine concentration after $240 \mathrm{~min}$. Thus, both irradiation and catalyst are necessary for the degradation to take place, which proves the photocatalytic nature of this reaction.

3.2. Quantum yield. As the lamp is longer than the annular reactor, it can be estimated that about $80 \%$ of the emitted light is efficient. UV fluorescent lamps have a yield of about $1 / 6$, that is about $6 \mathrm{~W}$ of irradiation power in the present case. Considering a mean energy of the emitted photons (around $365 \mathrm{~nm}$ ) have a mean energy of $0.33 \times 10^{6} \mathrm{~J} \cdot \mathrm{mol}^{-1}$, the irradiation rate was of $1.1 \times 10^{-3} \mathrm{E} \cdot \mathrm{min}^{-1}$ (where 1 Einstein $(\mathrm{E})=1$ mole of photons). For a maximum rate of $5 \times 10^{-2} \mathrm{mmol} \cdot \mathrm{min}^{-1}$ (see later), assuming that the irradiation flux was totally absorbed, the quantum yield would reach 0.05 .

3.3. Order with respect to atrazine. The effect of the initial atrazine concentration $\mathrm{C}_{0}$ on the initial rate of photocatalytic degradation, $\mathrm{r}_{0}$, is shown in Figure 2a. The rate is roughly proportional to the concentration, which corresponds to an initial kinetic order of one with respect to atrazine. This is in agreement with the simple Langmuir-Hinshelwood (LH) model. In the LH model, The reaction of degradation follows a rate determining step where an adsorbed molecule react with a reactive transient such as a $\mathrm{OH}^{\bullet}$ radical or a hole. If this attack is a minor process of disappearance of the reactive transient, the rate of reaction is proportional to the surface coverage by the pollutant. Assuming a simple Langmuir model of adsorption, the rate of reaction is given by the relationship [11]:

$$
\mathrm{r}_{0}=\mathrm{k}_{\mathrm{deg}} \frac{\mathrm{K}_{\mathrm{LH}} \cdot \mathrm{C}_{0}}{1+\mathrm{K}_{\mathrm{LH}} \cdot \mathrm{C}_{0}},
$$

where $\mathrm{K}_{\mathrm{LH}}$ is the adsorption constant, $\mathrm{C}$ the atrazine concentration in the aqueous phase and $\mathrm{k}_{\mathrm{deg}}$ a kinetic constant, which depends on various physico-chemical parameters including the irradiation conditions.

Relationship (17) can be rewritten in a linear form as:

$$
\frac{\mathrm{C}_{0}}{\mathrm{r}_{0}}=\left(\frac{1}{\mathrm{k}_{\mathrm{deg}}}\right)\left(\frac{1}{\mathrm{~K}_{\mathrm{LH}}}+\mathrm{C}_{0}\right)
$$

The data are consistent with this linear relationship as shown in Figure 2(b). From the values of $\mathrm{K}_{\mathrm{LH}}$ $\left(0.011 \mathrm{~L} \cdot \mu \mathrm{mol}^{-1}\right)$ and $\mathrm{k}_{\mathrm{deg}}\left(50 \mu \mathrm{mol} \cdot \mathrm{min}^{-1}\right)$, a theoretical curve has been plotted in Figure 2(a), which agrees with the experimental data.

As a consequence, the order with respect to atrazine is near to 1 at low concentration (that is $\mathrm{C}_{0}<50 \mu \mathrm{mol} \cdot \mathrm{L}^{-1}$ ), when eq. (17) reduces to eq. (19):

$$
\mathrm{r}_{0}=\mathrm{k}_{\mathrm{deg}} \mathrm{K}_{\mathrm{LH}} \mathrm{C}_{0} \text {, }
$$

whereas the order tends to a value of 0 at high concentration (beyond the present experimental range) where the rate would reach the limiting value $\mathrm{k}_{\mathrm{deg}}$.

If the intermediates do not compete severely with atrazine for adsorption and therefore for reaction with the reactive transient, the kinetics observed at initial time should hold during the reaction time.

In these conditions, the atrazine concentration should obey the relationship (20):

$$
\mathrm{V} \cdot \frac{\mathrm{dC}}{\mathrm{dt}}=-\mathrm{k}_{\mathrm{deg}} \frac{\mathrm{K}_{\mathrm{LH}} \cdot \mathrm{C}}{1+\mathrm{K}_{\mathrm{LH}} \cdot \mathrm{C}},
$$




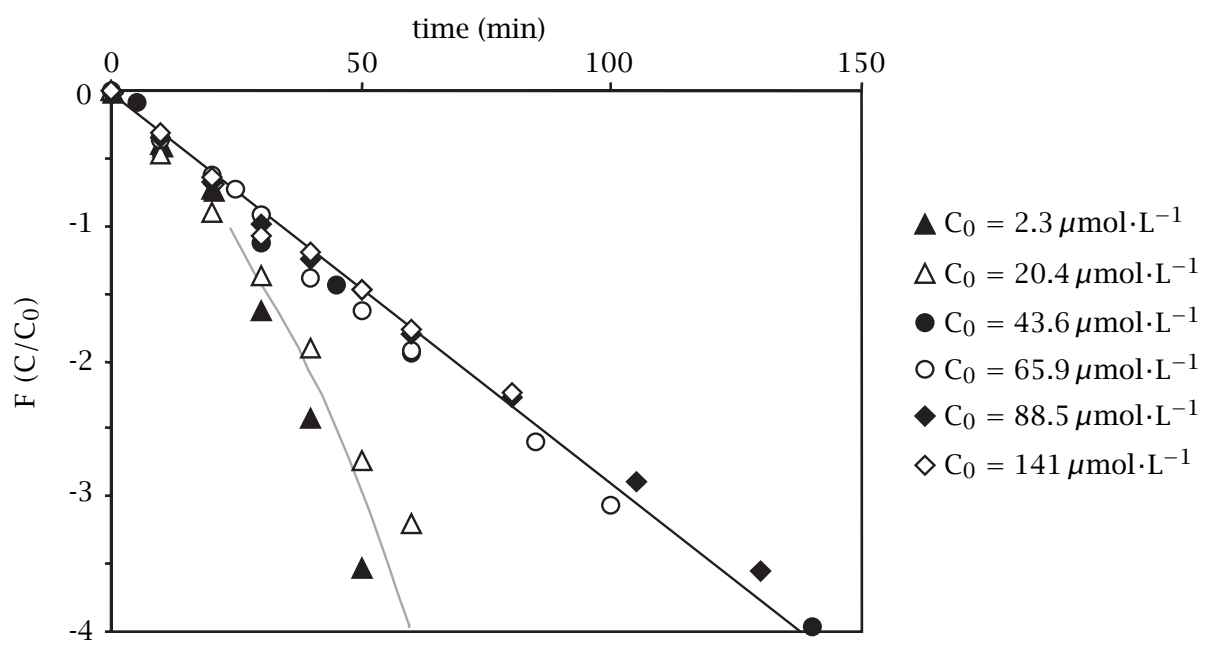

Figure 3. Checking of the kinetics during the photocatalytic degradation of atrazine. Variations of $\mathrm{F}\left(\mathrm{C} / \mathrm{C}_{0}\right)$ vs time (cf. eq. (20)).

Table 1. Effect of persulphate ions on the kinetics of atrazine photocatalytic degradation.

\begin{tabular}{ccc}
\hline persulphate concentration $\left(\mathrm{mmol} \cdot \mathrm{L}^{-1}\right)$ & \multicolumn{1}{c}{$r_{\text {initial with persulphate }}$} & duration of the accelerated kinetics (min) \\
\cline { 2 - 3 }$r_{\text {initial without persulphate }}$ & 1 & 0 \\
0.05 & $\sim 2$ & 10 \\
0.1 & $\sim 4$ & 20 \\
1.0 & $\sim 12$ & $(>10)$ \\
\hline
\end{tabular}

where $\mathrm{V}$ is the total volume of the suspension. Integrating (20) gives the relationship:

$$
\begin{aligned}
\mathrm{F}\left(\frac{\mathrm{C}}{\mathrm{C}_{0}}\right) & =\ln \left(\frac{\mathrm{C}}{\mathrm{C}_{0}}\right)+\mathrm{K}_{\mathrm{LH}} \cdot \mathrm{C}_{0}\left(\frac{\mathrm{C}}{\mathrm{C}_{0}}-1\right) \\
& =-\frac{\mathrm{k}_{\mathrm{deg}} \mathrm{K}_{\mathrm{LH}}}{\mathrm{V}} \cdot \mathrm{t} .
\end{aligned}
$$

The variations of $\mathrm{F}\left(\mathrm{C} / \mathrm{C}_{0}\right)$ vs time have been plotted in Figure 3 for various initial concentrations $\mathrm{C}_{0}$, using the value of $\mathrm{K}_{\mathrm{LH}}$ determined above. There is a good agreement with relationship (20) for most of the initial concentrations, with an identical slope. A pseudo auto-acceleration observed for low initial concentrations may be due to important experimental error in this concentration range. As a consequence, autoinhibition of the reaction can be considered as negligible, which means that the intermediates do not compete with atrazine for adsorption on the catalyst.

3.4. Effect of $\mathbf{p H}$. Typically, the $\mathrm{pH}$ value was of about 6 for the aerated suspension of $\mathrm{TiO}_{2}$. The effect of the $\mathrm{pH}$ on the reaction has been assessed by running experiments at $\mathrm{pH} 8$ by addition of $\mathrm{NaOH}$ and 3 by addition of $\mathrm{HNO}_{3}$ (as nitrate ions have a negligible adsorption on $\mathrm{TiO}_{2}$ [12]). The rate of photocatalytic degradation remained unchanged, within experimental error, showing that the $\mathrm{pH}$ had no effect in the range 3-8. This agrees with the concept that the effect of $\mathrm{pH}$, when observed [13] or not [14] , is due to an action on the reactant and not on the catalyst.

3.5. Effect of persulphate ions. Although the main advantage of the photocatalytic technique is to work without reagent (water and oxygen being present naturally), it is of interest to be able to improve the quantum yield by the addition of an oxidizing additive.

As shown in Figure 4, the persulphate ions $\mathrm{S}_{2} \mathrm{O}_{8}{ }^{2-}$ had indeed an accelerating effect on the reaction. This anion can be reduced on the catalyst following the reaction [15]:

$$
\mathrm{S}_{2} \mathrm{O}_{8}{ }^{2-}+\mathrm{e}^{-} \longrightarrow \mathrm{SO}_{4}{ }^{2-}+\mathrm{SO}_{4}{ }^{-\bullet},
$$

producing a very reactive ion $\mathrm{SO}_{4}{ }^{-\bullet}$, able to attack organic compounds by abstraction of a hydrogen atom or addition on unsaturated molecules.

The accelerating effect was only observed for a partial extent of reaction. This accelerated degradation was then followed by the "standard" degradation of atrazine on its own as shown in Figure 4 for persulphate ion concentrations of 0.05 and $0.1 \mathrm{~mol} \cdot \mathrm{L}^{-1}$. Such an effect is likely to be due to the consumption of the additive in the oxidizing process. As shown in Table 1, 


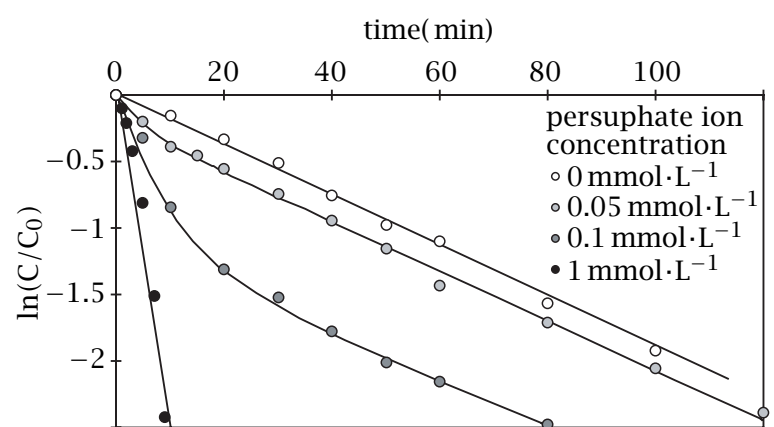

Figure 4. Acceleration of the photocatalytic degradation of atrazine by persulphate ions.

the initial rate of atrazine degradation was nearly proportional to the initial persulphate concentration at moderate concentrations. The duration of this fast kinetics was nearly proportional to the initial persulphate concentration, which suggests a zero order kinetics of the photocatalytic degradation of persulphate with respect to the reactant itself.

In conclusion, the photocatalytic degradation of atrazine is significantly improved and such an additive could be used in an industrial process, providing the added quantity is in relation with the amount of pollutant to be degraded.

3.6. Codegradation. Usually, several organic pollutants can be present in the same natural source of water. In such a codegradation, there may be either additional or competitive degradation between the pollutants. In order to study this phenomenon, the codegradation of atrazine with salicylic acid, phenol and pyridine as a model copollutant has been carried out using similar concentrations in atrazine and copollutant (about $50 \mu \mathrm{mol} \cdot \mathrm{L}^{-1}$ ). The experimental evolutions of the atrazine relative concentration $\left(\mathrm{C} / \mathrm{C}_{0}\right)$ under these conditions have been plotted in Figures 5(a), (b) and (c) where salicylic acid, phenol and pyridine are the copollutants respectively.

Figure 5(b) shows that in the [atrazine-phenol] codegradation, phenol degradation is practically unchanged whereas atrazine degradation is much inhibited. A similar but stronger effect is observed in the [atrazine-salicylic acid] codegradation (Figure 5(a)) where atrazine degradation is only effective once the copollutant has been degraded. A similar behaviour has already been reported in the [atrazine-4-chrophenol] and [Benzamide-4-Hydroxybenzamide acid] [17] system. However, in the [atrazine-pyridine] codegradation (Figure 5(c)), atrazine degradation is only slightly inhibited (unfortunately, it has not been possible to follow the pyridine concentration in this system).

These observations suggest that competitive adsorption might be the critical process in the degradation competition. This situation can be simulated by
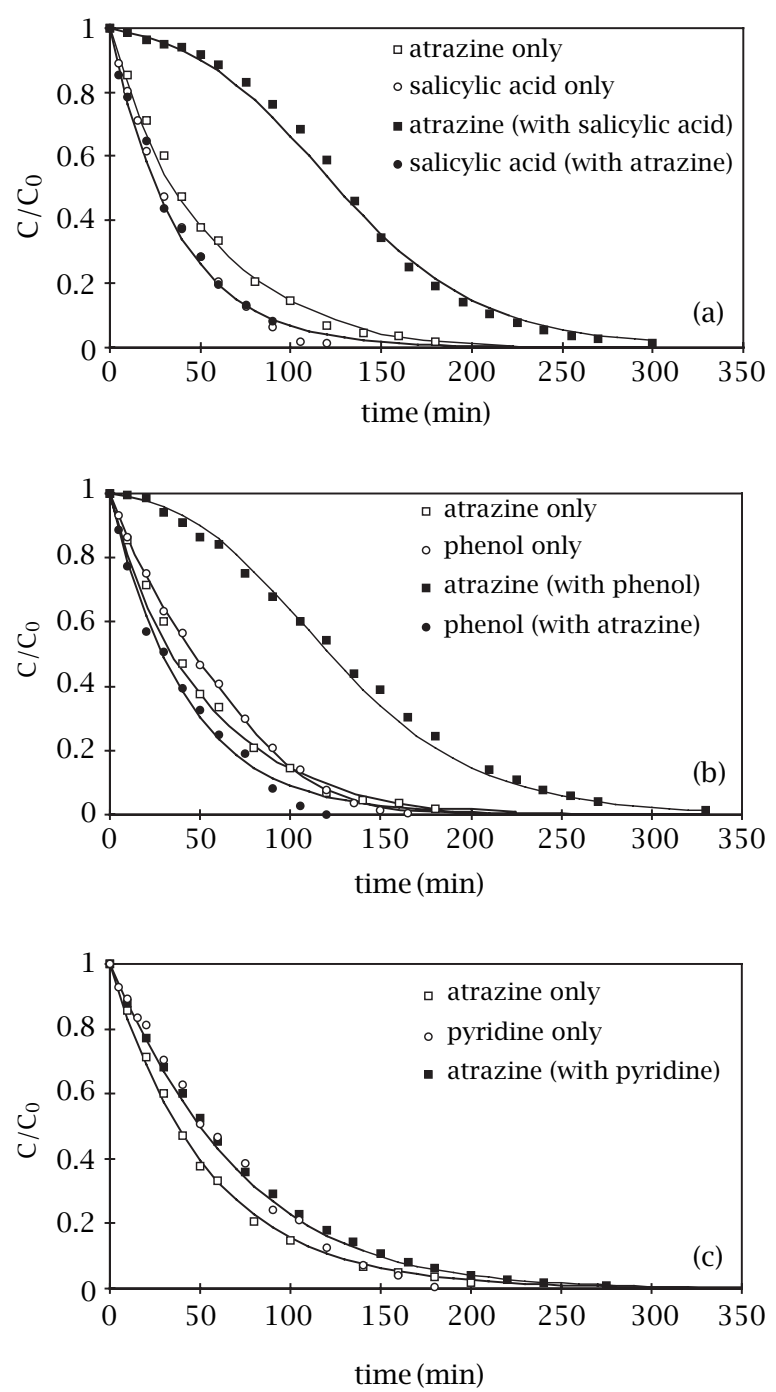

Figure 5. (a) Competitive photocatalytic degradation of atrazine and salicylic acid. Initial concentrations: atrazine $46.4 \mu \mathrm{mol} \cdot \mathrm{L}^{-1}$; salicylic acid $47 \mu \mathrm{mol} \cdot \mathrm{L}^{-1}$. (b) Competitive photocatalytic degradation of atrazine and phenol. Initial concentrations: atrazine $46.4 \mu \mathrm{mol} \cdot \mathrm{L}^{-1}$; phenol $50 \mu \mathrm{mol} \cdot \mathrm{L}^{-1}$. (c) Competitive photocatalytic degradation of atrazine and pyridine. Initial concentrations : atrazine $46.4 \mu \mathrm{mol} \cdot \mathrm{L}^{-1}$; pyridine $50 \mu \mathrm{mol} \cdot \mathrm{L}^{-1}$.

an approximate model where the copollutant inhibits atrazine degradation but atrazine does not alter significantly the copollutant degradation.

The rate of atrazine degradation can be written, taking into account the competitive adsorption:

$$
\mathrm{r}=\mathrm{k}_{\mathrm{deg}}\left(\frac{\mathrm{K}_{\mathrm{LH}} \cdot \mathrm{C}}{1+\mathrm{K}_{\mathrm{LH}} \cdot \mathrm{C}+\mathrm{K}_{\mathrm{LH}}^{\prime} \cdot \mathrm{C}^{\prime}}\right) \text {, }
$$

where $\mathrm{K}_{\mathrm{LH}}^{\prime}$ is the adsorption constant and $\mathrm{C}^{\prime}$ the concentration of the copollutant. The evolution of the 
Table 2. Fitting parameters for the various [atrazine-copollutant] systems.

\begin{tabular}{lccc}
\hline copollutant & $\mathrm{k}\left(\mathrm{min}^{-1}\right)$ & $\mathrm{k}^{\prime}\left(\mathrm{min}^{-1}\right)$ & $\mathrm{K}^{\prime}$ \\
\hline salicylic acid & $2.0 \times 10^{-2}$ & $2.7 \times 10^{-2}$ & 18 \\
phenol & $1.92 \times 10^{-2}$ & $2.2 \times 10^{-2}$ & 9 \\
pyridine & $1.85 \times 10^{-2}$ & $1.3 \times 10^{-2}$ & 0.5 \\
\hline
\end{tabular}

concentration of atrazine must therefore obey the relationship:

$$
\mathrm{r}=-\mathrm{V}\left(\frac{\mathrm{dC}}{\mathrm{dt}}\right)
$$

Under some simplifying assumptions, it is possible to get the expression of $\mathrm{C}(\mathrm{t})$ : $\mathrm{a})$ a pseudo first-order kinetics of degradation of the copollutant, independent of the presence of atrazine, leading to a quasi exponential decay in concentration (where $C_{0}^{\prime}$ is the initial concentration in copollutant):

$$
\mathrm{C}^{\prime}=\mathrm{C}_{0}^{\prime} \cdot \exp \left(-\mathrm{k}^{\prime} \cdot \mathrm{t}\right)
$$

b) a near-first order for the degradation of atrazine in the concentration range (initial concentration of about $10 \mu \mathrm{mol} \cdot \mathrm{L}^{-1}$ ), that is $\mathrm{K}_{\mathrm{LH}} \cdot \mathrm{C} \ll 1$ in eq. (23). Introducing these approximations in eqs. (23) and (24) and integrating leads to the following expression for atrazine concentration:

$$
\frac{\mathrm{C}(\mathrm{t})}{\mathrm{C}_{0}}=\exp \left\{-\mathrm{k} \cdot\left[\mathrm{t}+\frac{1}{\mathrm{k}^{\prime}} \ln \left(\frac{1+\mathrm{K}^{\prime} \cdot \exp \left(-\mathrm{k}^{\prime} \cdot \mathrm{t}\right)}{1+\mathrm{K}^{\prime}}\right)\right]\right\},
$$

with:

$$
\mathrm{k}=\frac{\mathrm{k}_{\mathrm{deg}} \mathrm{K}_{\mathrm{LH}}}{\mathrm{V}}, \quad \mathrm{K}^{\prime}=\mathrm{K}_{\mathrm{LH}}^{\prime} \mathrm{C}_{0}^{\prime}
$$

This relationship has been plotted as full lines in Figures 5(a), (b) and (c) and agrees with the experimental data using the fitting parameters $\mathrm{k}, \mathrm{k}^{\prime}$ and $\mathrm{K}^{\prime}$ given in Table 2.

Although the various compounds have similar intrinsic kinetics properties ( $\mathrm{k}$ or $\mathrm{k}^{\prime}$ ), phenol and particularly salicylic acid exhibit an higher adsorption as shown by values of $\mathrm{K}$ much higher than the corresponding term $\mathrm{K}_{\mathrm{LH}} \cdot \mathrm{C}_{0}=0.5$ for atrazine. This may be surprising as phenol is known to adsorb very little on the catalyst [18]. However, a competition effect could take place if it is considered that this competition takes on few specific "active" sites, which only can lead to the degradation, whereas common adsorption measurements are relative to the whole surface. Accordingly, most of salicylic acid or phenol is degraded before atrazine can adsorb enough so as to be degraded. Pyridine exhibit similar properties as atrazine and this results in a moderate inhibition of the photocatalytic degradation of atrazine.

\section{CONCLUSION}

Atrazine is efficiently degraded by the photocatalytic process and this experimental study could give useful information for the design of an industrial elimination processing unit. The kinetics obeys satisfactorily the Langmuir-Hinshelwood model, from which an adsorption constant has been determined. This degradation can be accelerated by persulphate ions, but the consumption af this additive requires a careful dosing in an actual process. The study of the codegradation of atrazine with other pollutants in satisfactorily represented by a competitive coadsorption model on active sites. As a consequence low adsorbing compounds like atrazine or pyridine only takes place when other high adsorbing compounds such as salicylic acid and phenol are degraded in the first place.

\section{REFERENCES}

[1] J. Perot and A. Deguin, Water Supply 10 (1992), 157.

[2] R. L. Jolley and W. W. Pitt, Chemistry of Wastewater Technology, (A. J. Rubin, Ed.), Ann Arbor Sci., Ann Arbor, Mich., 1978.

[3] F. J. Beltran, G. Ovejero, and B. Acedo, Wat. Res. 27 (1993), 1013.

[4] O. Le Brun, N. Merlet, J. P. Croue, and M. Doré, Sciences et techniques de l'eau 26 (1993), 97.

[5] J. De Laat, Doré, and H. Suty, Revue des Sciences de l'Eau 8 (1995), 23.

[6] R. A. Larson, M. B. Schlauch, and K. A. Marley, J. Agric. Food Chem. 39 (1991), 2057.

[7] J. Arantegui, J. Prado, E. Chamarro, and S. Esplugas, J. Photochem. and Photobiol. A: chem. 88 (1995), 65.

[8] E. Pelizzetti, V. Carlin, C. Minero, and M. Grätzel, New J. Chem. 15 (1991), 351.

[9] M. R. Hoffmann, S. T. Martin, W. Choi, and D. W. Bahnemann, Chemical Reviews 95 (1995), 69.

[10] E. Pelizzetti, V. Maurino, C. Minero, V. Carlin, E. Pramauro, O. Zerbinati, and M. Tosato, Environ. Sci. Technol. 24 (1990), 1559.

[11] G. Scacchi, M. Bouchy, J. F. Foucaut, and O. Zahraa, Cinétique et Catalyse, collection Génie des Procédés de l'École de Nancy, Ed. TEC \& DOCLavoisier, Paris, 1996.

[12] H. Y. Chen, O. Zahraa, and M. Bouchy, J. of Photochem. and Photobiol. A: Chem. 108 (1997), 37. 
[13] S. Tunesi and M. Anderson, J. Phys. Chem. 95 (1991), 3399.

[14] H. Y. Chen, O. Zahraa, M. Bouchy, F. Thomas, and J. Y. Bottero, J. of Photochem. and Photobiol. A: Chem. 85 (1995), 179.

[15] C. Minero, E. Pelizzetti, S. Malato, and J. Blanco, Solar Energy 56 (1996), 411.
[16] F. D. Ollis, E. Pelizzetti, and N. Serpone, Environ. Sci. Technol. 25 (1991), 1522.

[17] A. Piscopo, Ph.D. Thesis, METZ University, 2002.

[18] C. Dorion, Etude de Catalyseurs Supportés pour Réacteur Photocatalytique de Traitement des Eaux, PhD Thesis, INPL-Nancy, France, 1996. 


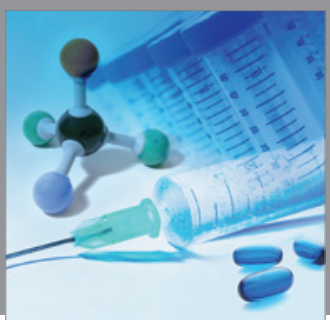

International Journal of

Medicinal Chemistry

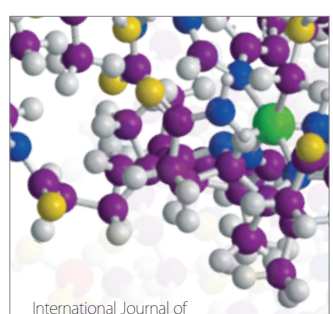

Carbohydrate Chemistry

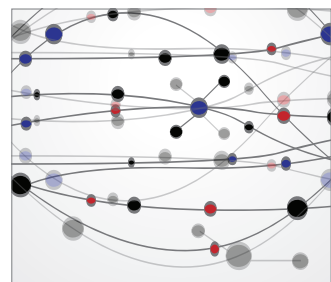

The Scientific World Journal
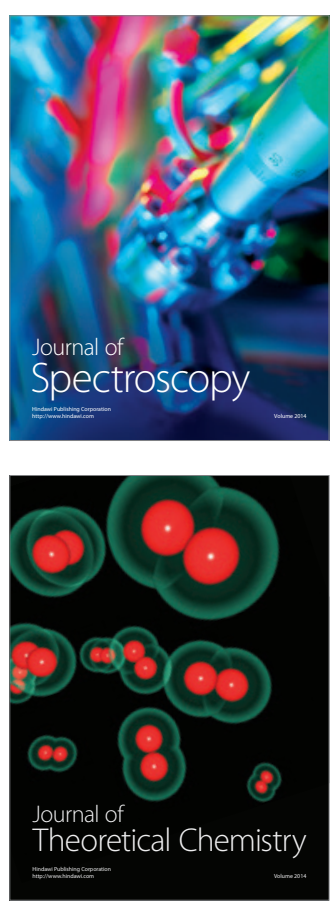
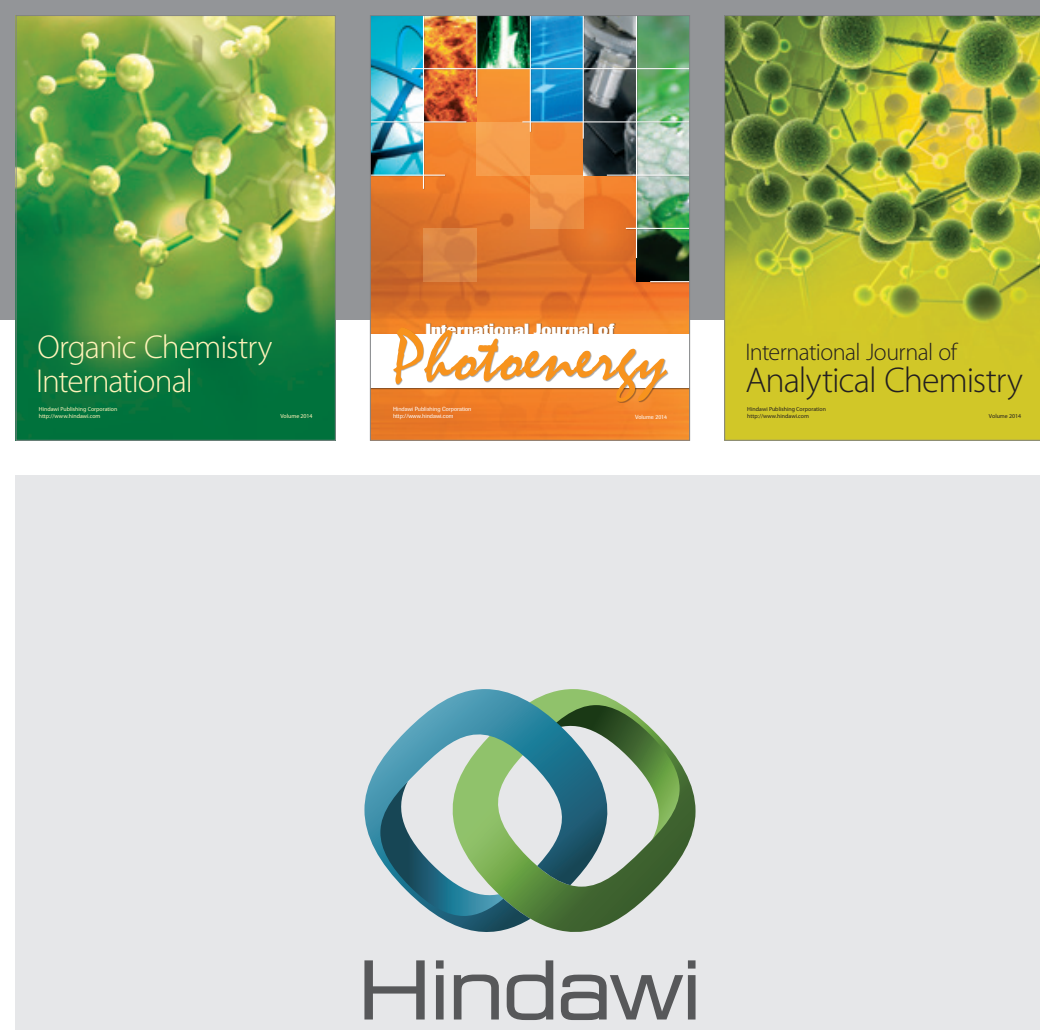

Submit your manuscripts at

http://www.hindawi.com
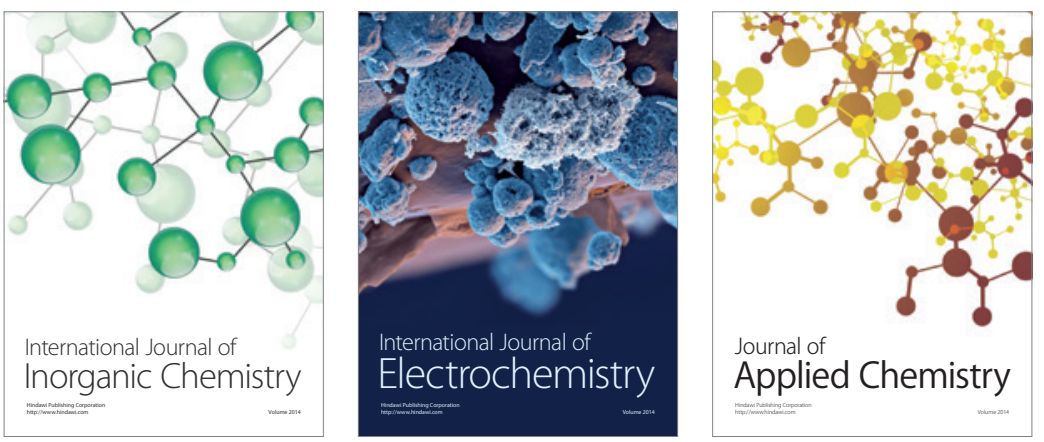

Journal of

Applied Chemistry
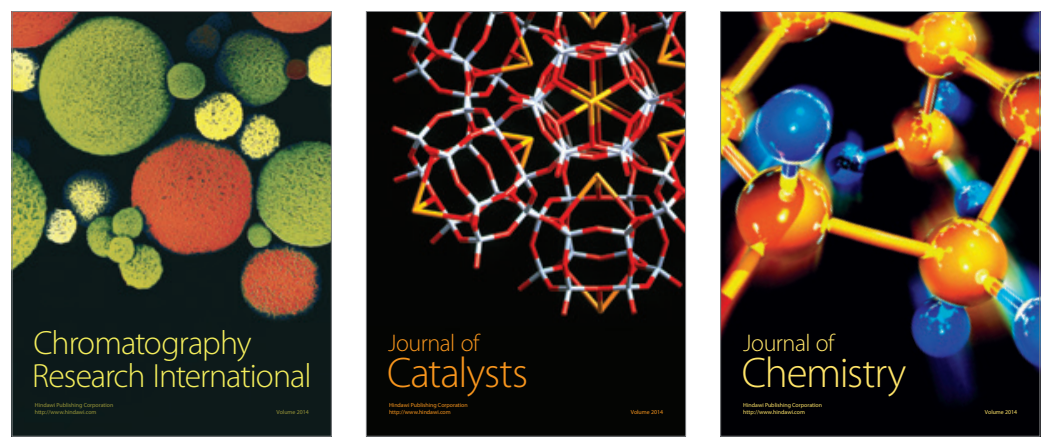
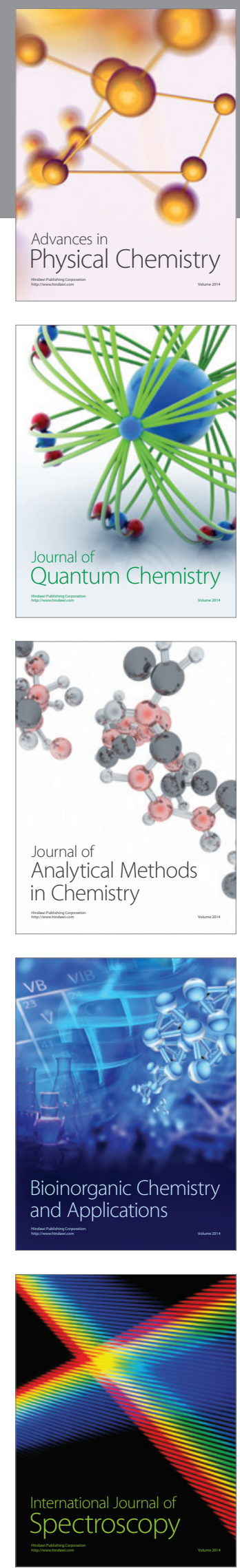